\title{
In silico Evaluation of Phytocompounds of Neolamarckia cadamba (Roxb.) Stem Bark for Anticancer Activity
}

\author{
Ravi Kumar Pola ${ }^{1, *}$, Srinu Naik Sapavatu² and Madhava Reddy Bommineni ${ }^{1}$ \\ 'Department of Pharmacognosy, G. Pulla Reddy College of Pharmacy, Hyderabad, Telangana, INDIA. \\ 2Deaprtment of Chemical Engineering, University College of Technology, Osmania University, Hyderabad, Telangana, INDIA.
}

\begin{abstract}
Objectives: Molecular docking studies are efficient tools to study the biopharmaceutical and pharmacokinetic parameters of drug compounds. The present study aimed to determine the in-vitro cytotoxic activity of stem bark extract of Neolamarckia cadamba (Roxb.) and to evaluate specific anticancer potential of selected phytocompounds of the bark using in silico molecular docking study. Materials and Methods: MTT assay was performed on MCF7, A549 and HepG2 cell lines. TLC screening conducted on all extracts and $80 \%$ hydro alcoholic extract subjected to fractionation using column chromatography. Selected fractions were analysed by GC-MS. Few of the compounds reported in GC-MS were docked on anticancer target proteins using autodockvina. Results: The $\mathrm{IC}_{50}$ values of the extract were found as $149.7 \mu \mathrm{g} / \mathrm{ml}, 51.5 \mu \mathrm{g} / \mathrm{ml}$ and $60.9 \mu \mathrm{g} / \mathrm{ml}$ respectively. TLC in solvent system containing toluene, ethyl acetate and diethyl amine $(7: 2: 1)$ revealed 12 spots when sprayed with vanillin sulphuric acid and 6 spots in solvent system containing methanol and chloroform (1.5:8.5). 20 fractions were collected from column chromatography technique. GC-MS chromatogram
\end{abstract}

of fraction-3 shown 8 compounds and that of fraction-4 resulted in 19 compounds respectively. Binding energies and interactions of docked compounds are comparable to those of standards selected. Conclusion: Neolamarckia cadamba stem bark extract had shown excellent cytotoxic activity and the docked compounds also revealed the same indicating remarkable anticancer potential of the extract.

Key words: Autodockvina, Column chromatography, GC-MS analysis, Ligand- protein interaction, Molecular docking, MTT assay.

\section{Correspondence}

Prof. P Ravi Kumar,

Asst.Professor, Department of Pharmacognosy, G.Pulla Reddy College of Pharmacy, Mehdipatnam, Hyderabad- 500028, Telangana, INDIA.

Email id: pravikumar@gprcp.ac.in

DOI: 10.5530/ijpi.2021.3.53

\section{INTRODUCTION}

Plants and trees are providing food and medicines human beings and animals from the start of life on the earth. The tribes had been communicated their knowledge on medicinal plants and their application to next generations practically. The treatise written by ancient healers like charaka samhitha, susrutha samhitha etc. are listing ethno-medicinal uses of different plants. Now, in the present technology era researchers are evaluating specific pharmacological activities of many plants using modern methods of screening basing on ethno medicinal uses. ${ }^{1}$ The latest techniques of drug evaluation involving computer aided tools became a boon to screen several compounds within a short period of time. These methods are providing pharmacodynamic and pharmacokinetic data of phytocompounds which can be compared with that of standard substances. Thus, in silico molecular docking studies boosted up research in the field of biomedical sciences and providing suitable drug candidates economically. This approach became an eco-friendly experimental tool. ${ }^{2}$ Isolated phytocompounds from plant extracts have been screened extensively to exploit the plants and trees for safe and effective medicinal compounds to treat many chronic disorders. ${ }^{3}$ Cancer became a challenge to human race which rising the death rate every year all over the world. In spite of many synthetic drugs and natural products derived drugs, cancer patients' suffering is still continuing. The cost regimens are unbearable for most of the population on the globe. Natural products are showing less or nil side effects during treatment of different cancers forms. ${ }^{4}$ So, still many plants can be screened to prove their anticancer property.

Neolamarkia cadamba (Roxb.) reported to possess a fine array of ethno medicinal uses i.e. in treatment of swelling, fever, diabetes, inflammation of gums, mouth ulcers, glycosuria, muscular pains, diarrhoea, irritable bowel syndrome, blood related disease, leprosy etc. Recent review reveals its anti-diabetic, analgesic, antipyretic, anti-inflammatory, anti-diarrhoeal, diuretic, laxative, hepatoprotective, hypolipidimic, antioxidant, antiproliferative, anthelmintic, antifungal, anti-parasitic, anti-filarial, antimalarial, anti-venom, abortificient, immunomodulatory and anticancer activities. These activities were attributed to Phytochemistry of the tree which states the presence of rich amount of alkaloids, steroidal derivatives, terpenoids, flavonoids, phenolics. Few bioactive compounds were isolated and studied by earlier scientific investigators in different geographic regions of country. ${ }^{5}$ The present investigation focused on isolation of compounds form the stem bark of the tree native to Telangana region and evaluation of their specific anticancer potential using molecular docking studies.

\section{MATERIALS AND METHODS}

\section{Collection and Identification of plant material}

Twig of the tree, Neolamarckia cadamba (Anthocephalus cadamba) with leaves and flowers was collected in the month of October near Bapughat, Langar house, Mehdipatnam, Hyderabad, Telangana, India. Specimen voucher (GPRCP/PRK/191018) of the same prepared and preserved in department of Pharmacognosy. Bark of the tree was collected and shade dried for two weeks. The voucher specimen was identified and authenticated by Mr. PV Prasanna, scientist 'F' at botanical survey of India, Attapur, Hyderabad, Telangana.

This is an open access article distributed under the terms of the Creative Commons Attribution-NonCommercial-ShareAlike 4.0 License, which allows others to remix, tweak, and build upon the work non-commercially, as long as the author is credited and the new creations are licensed under the identical terms. 
Procurement of reagents, chemicals, solvents and cell

lines

Dichloromethane, n-Heaxane (LR) and TLC silica gel $60 \mathrm{~F}_{254}$ (Merk) plates, silica gel for column chromatography were purchased from Sri Venkateshwara scientific suppliers, Hyderabad. Ethanol (RS) was procured from prohibition and excise Department of Telangana state govt. DMEM (Dulbecco's Modified Eagles Medium), MTT [3-(4,5-dimethylthiazol2-yl)-2,5- diphenyl tetrazolium bromide], trypsin, EDTA phosphate buffered saline (PBS) were purchased from Sigma Chemicals Co. (St. Louis, MO). Fetal bovine serum (FBS) was purchased from Gibco and 96 well plates purchased from eppendroff India. Cancer cell lines were bought from NCCS, Pune, and Maharashtra. The cells were maintained in MEM, supplemented with $10 \%$ FBS and antibiotic solution (penicillin- $0.5 \mathrm{mmolL}^{-1}$ ), in an atmosphere of $5 \% \mathrm{CO}_{2} / 95 \%$ air at $37^{\circ} \mathrm{C}$.

\section{Extraction, phytochemical screening and thin layer chromatography}

The dried bark was powdered and $1.0 \mathrm{~kg}$ powder was extracted successively using $\mathrm{n}$-hexane, dichloromethane and $80 \%$ ethanol in soxhlet extractor. Solvent from extracts recovered in rotavapor and the extracts were dried under vacuum. Yield of the extracts was calculated and were stored in a dessicator. $80 \%$ alcoholic extract i.e. Neolamarckia cadamba hydro alcoholic extract (NCHAE) was tested using different chemical reagents to check phytochemical nature. TLC analysis of NCHAE was performed with different solvent systems to predict Phytochemistry and to find approximate number of compounds in the extract.

\section{MTT assay}

MTT assay was carried out for NCHAE on MCF7 cell lines at IIT Hyderabad whereas assay on A549 and HepG2 cell lines was done at Synteny Labs, Nallakunta, Hyderabad. MTT assay is a colorimetric assay which measures the reduction of yellow 3-(4, 5-dimethythiazol- 2-yl)2, 5-diphenyl tetrazolium bromide (MTT) by mitochondrial succinate dehydrogenase. The assay was performed with five concentrations of extract i.e. 5, 10, 25, 50 and $100 \mu \mathrm{g} / \mathrm{ml}$, in triplicates on HepG2 and A549 cells. $50,100,150$ and $200 \mu \mathrm{g} / \mathrm{ml}$ concentrations were used on MCF-7 cells. Tryphan blue assay was performed on trypsinized cells to know viable cells in cell suspension. Then, cells were counted by haemocytometer and seeded at a density of $5.0 \times 10^{3}$ cells/well in $100 \mu \mathrm{l}$ media in 96 well plate containing culture medium and incubated overnight at $37^{\circ} \mathrm{C}$. Spent media was removed and $100 \mu \mathrm{l}$ of fresh media was added and different concentrations of extract solution added to represented wells in 96 plates. After $48 \mathrm{hrs}$, the extract solution discarded. Fresh medium and MTT solution $\left(0.5 \mathrm{mg} / \mathrm{mL}^{-1}\right)$ added to each well and plates were incubated at $37^{\circ} \mathrm{C}$ for $3 \mathrm{hrs}$. The optical density of solubilised crystals in DMSO was measured at $570 \mathrm{~nm}$ on a microplate reader. The percentage growth inhibition was calculated using the following formula.

$$
\% \text { Inhibition }=\frac{100(\text { Control }- \text { Treatment })}{\text { Control }}
$$

The $\mathrm{IC}_{50}$ values were calculated from linear regression equation i.e. $\mathrm{Y}=\mathrm{mx}+\mathrm{C}$, where $\mathrm{Y}=50$. Values of $\mathrm{m}$ and $\mathrm{C}$ were taken from the \%viability graph. ${ }^{6,7}$

\section{Column chromatography}

Adsorption column chromatographic technique was followed. 10gm of NCHAE was dissolved in methanol, adsorbed onto silica gel and dried. Column was packed using wet packing method. The adsorbed extract was introduced onto the column as per the standard procedure and gradient elution technique was employed. Mobile phase was allowed to flow through the column in the increasing order of polarity starting from pure n-Hexane; n-hexane and ethyl acetate; ethyl acetate; ethyl acetate and methanol and pure methanol at the end. The mobile phase mixture compositions were 90:10, 80:20, 70:30, 60:40, 50:50, 40:60, 30:70, 20:80 and 10:90 respectively. Each fraction of $25 \mathrm{ml}$ was collected and monitored using TLC. The fractions with similar TLC profile were pooled and 20 fractions were prepared finally. These were further monitored by performing TLC.

\section{Characterization of NCHAE by GC-MS Analysis}

Based on TLC profile, Fraction 3 and 4 were subjected to GC-MS screening. The Clarus 680 GC (Perkin Elmer) was used for the analysis. A fused silica column, packed with Elite-5MS (5\% biphenyl 95\% dimethyl polysiloxane, $30 \mathrm{~m} \times 0.25 \mathrm{~mm} \mathrm{ID} \times 250 \mu \mathrm{m})$ was employed. The components were separated using Helium as carrier gas at a constant flow of $1 \mathrm{ml} / \mathrm{min}$. The injector temperature was set at $260^{\circ} \mathrm{C}$ during the chromatographic run. $1 \mu \mathrm{l}$ of extract solution injected onto the column. The oven temperature was increased gradually, $60^{\circ} \mathrm{C}(2 \mathrm{~min})$, followed by $300^{\circ} \mathrm{C}$ at the rate of $10^{\circ} \mathrm{C} \mathrm{min}$, then held at $300^{\circ} \mathrm{C}$ for $6 \mathrm{~min}$. Transfer line and ionization source temperature of mass detector were maintained at $230^{\circ} \mathrm{C}$. Electron impact ionization mode was maintained at $70 \mathrm{eV}$. A scan time of $0.2 \mathrm{sec}$ and scan interval of $0.1 \mathrm{sec}$ were maintained. The fragments from 40 to 600 Daltons were collected and detected. The spectrums of the components were compared with the database of spectrum of known components stored in the GC-MS NIST (2008) library. ${ }^{8}$

\section{In silico Study \\ Protein preparation}

VEGFR2 kinase (lung cancer target), HER2 (erbB2) kinase (breast cancer target) and EGFR tyrosine kinase (liver cancer target) were selected basing on the cell lines selected for cytotoxic activity.The 3D crystal structure of VEGFR2 kinase (PDB ID: 4ASD, Resolution: $2.03 \AA$ ), HER2 (ErbB2) kinase (PDB ID: 3PP0, Resolution: $2.25 \AA$ ) and EGFR tyrosine kinase (PDB ID: $4 \mathrm{HJO}$, Resolution: $2.75 \AA$ ) were retrieved from protein data bank (RCSB PDB). Protein preparation was performed by removing the bound water molecules, adding polar hydrogen and computing the kollman charges using auto dock tools. Grid was generated to define the active site in the protein using Auto Dock tools.

\section{Ligand preparation and docking}

Compound- A (PRK3-RT27.143), compound-B (PRK4-RT19.420), compound-C (PRK4-RT19.855) and compound-D (PRK4- RT20.651) were considered as ligands. All the ligands were sketched using chem-draw and saved in SDF format. These ligands were cleaned in $2 \mathrm{D}$ and converted 3D structures. Energy was minimized and ionization states were preserved. Initially all the structures were written in molecular format then saved in PDB format using discovery studio visualizer. The ligands were further recognised by sing AutoDock Vina tools. The interactions of these molecules with those 3 target proteins were studied using molecular docking calculations, which were performed by AutoDock Vina. Molecular docking was performed using the AutoDockVina interface. Standard drugs were also docked similarly. The binding energies and interactions with target protein were recorded and interpreted to explore hydrogen bonding, hydrophobic interactions and Vander-wall forces. ${ }^{9-13}$

\section{RESULTS}

\section{Extraction, phytochemical screening and TLC}

The weight of dried NCHAE was found to be 50.350gm (5.035\%). Phytochemical screening of NCHAE had shown positive results for alkaloids, glycosides, carbohydrates, steroids and tannins as shown in 
Table 1. TLC plate revealed 6 clear spots in chromatogram developed in solvent system containing methanol and chloroform (1.5:8.5) when sprayed with dragendorff's reagent and is represented as 'A' in Figure 1. The TLC chromatogram developed in solvent system containing toluene, ethyl acetate and diethyl amine (7:2:1) shown 12 spots after derivatization with vanillin sulphuric acid reagent and is represented as 'B' in Figure 1.

\section{MTT assay}

The $\mathrm{IC}_{50}$ values of the extract are depicted in the Table 2.

\section{GC-MS characterization}

GC-MS chromatograms of fraction- 3 and 4 are depicted in the Figure 2. Fraction-3 (PRK-3) had shown 8 prominent compounds and those are listed in Table 3. The compound with highest percentage area is BetaD-Lyxofuranoside, thio-decyl (Compound-A). Fraction-4 (PRK-4) had

Table 1: Phytochemical screening of NCHAE.

\begin{tabular}{ccc}
\hline Test & $\begin{array}{c}\text { Phytochemical } \\
\text { constituent }\end{array}$ & NCHAE \\
performed & Alkaloids & ++ \\
Dragendorf's & Alkaloids & ++ \\
Wagner's & Alkaloids & + \\
Picric acid & Alkaloids & ++ \\
Mayer's & & \\
& Glycosides & - \\
Born-trager's & Glycosides & + \\
Modified Born- & & \\
Trager's & Saponins & ++ \\
Foam & Carbohydrates & ++ \\
Molisch's & Carbohydrates & + \\
Fehling's & Aminoacids & - \\
Ninhydrin & Steroids & ++ \\
Salkowski & Steroids & \\
Liebermann-Burchard & & - \\
Shinoda & Flavonoids & ++ \\
Fecl & Tannins & - \\
Lead acetate & Tannins & \\
& &
\end{tabular}

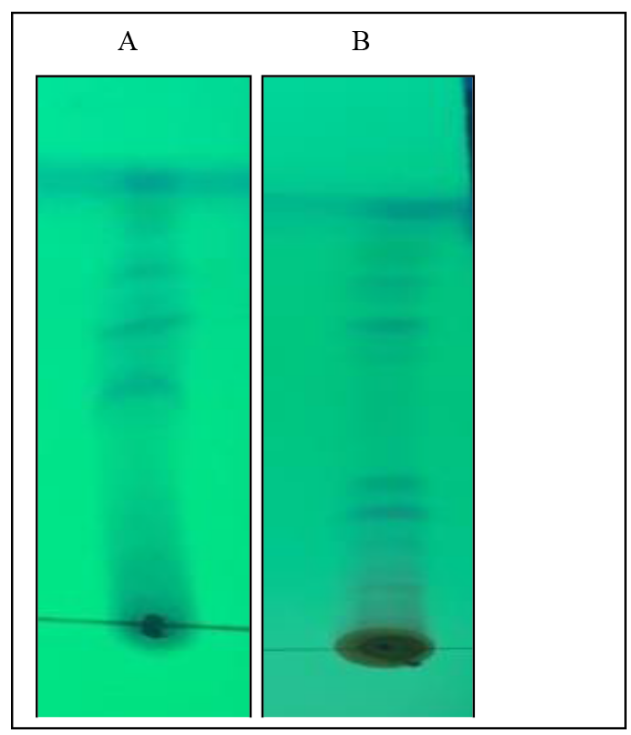

Figure 1: TLC Profile of NCHAE.
Table 2: MTT Assay of NCHAE.

\begin{tabular}{ccc}
\hline S. No & Cell line & $\begin{array}{c}\mathrm{IC}_{50} \text { Value } \\
(\mu \mathrm{g} / \mathrm{ml})\end{array}$ \\
\hline 1 & MCF7 & 113.06 \\
2 & A549 & 60.15 \\
3 & HepG2 & 68.85 \\
\hline
\end{tabular}

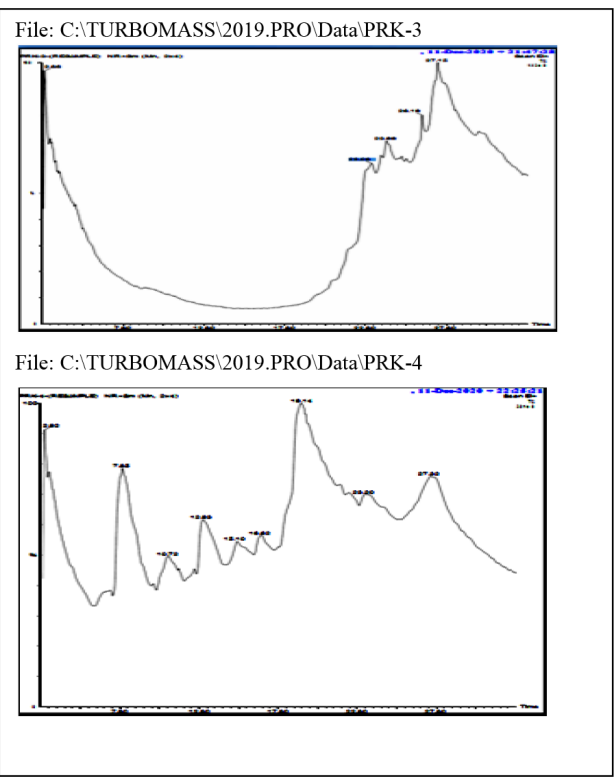

Figure 2: GC-MS Chromatogram of Fraction.

Table 3: Peak table of Fraction-3 (PRK3).

\begin{tabular}{cccc}
\hline S.No & RT & Area & Area\% \\
\hline 1 & 23.047 & $32,135,438.0$ & 12.474 \\
2 & 23.987 & $49,756,012.0$ & 19.313 \\
3 & 24.942 & $7,978,410.5$ & 3.097 \\
4 & 25.237 & $6,730,562.0$ & 2.613 \\
5 & 26.208 & $32,879,430.0$ & 12.762 \\
6 & 27.143 & $118,078,384.0$ & 45.833 \\
7 & 29.699 & $5,386,071.5$ & 2.091 \\
8 & 30.014 & $4,684,062.5$ & 1.818 \\
\hline
\end{tabular}

shown 15 compounds which are shown in Table 4. 3compounds were selected for docking basing on percentage area of the peaks. Those are 1H-Imidazole, 2-(Diethoxymethyl) at RT19.420 (Compound-B); 3-Butene-1, 2-Diol,1-(2-Furanyl) at RT 19.855 (Compound-C) and 7-Hydroxy-3-(1, 1-Dimethylprop-2-Enyl)Coumarin at RT 20.651 (Compound-D). The names were displayed as per NIST library.

\section{In silico study}

The interactions of the selected ligands on the target proteins are depicted in Figure 3-5.

\section{DISCUSSION}

The phytochemical screening of NCHAE revealed the presence of alkaloids, steroids, saponins and tannins. The solvent system used 
Table 4: Peak table of Fraction-4(PRK4).

\begin{tabular}{cccc}
\hline S.No & RT & Area & Area\% \\
\hline 1 & 19.035 & $1,938,414.9$ & 5.277 \\
2 & 19.125 & $4,140,196.5$ & 11.270 \\
3 & 19.420 & $4,324,465.0$ & 11.772 \\
4 & 19.630 & $1,537,917.4$ & 4.186 \\
5 & 19.695 & $1,699,142.4$ & 4.625 \\
6 & 19.855 & $2,638,130.0$ & 7.181 \\
7 & 20.371 & $1,662,357.1$ & 4.525 \\
8 & 20.506 & $1,613,139.6$ & 4.391 \\
9 & 20.651 & $1,804,600.2$ & 4.912 \\
10 & 20.781 & $1,509,613.1$ & 4.109 \\
11 & 21.606 & $2,168,298.8$ & 5.902 \\
12 & 22.156 & $1,952,214.2$ & 5.314 \\
13 & 22.356 & $1,963,046.9$ & 5.344 \\
14 & 27.183 & $5,699,802.5$ & 15.516 \\
15 & 27.608 & $2,084,716.1$ & 5.675 \\
\hline
\end{tabular}

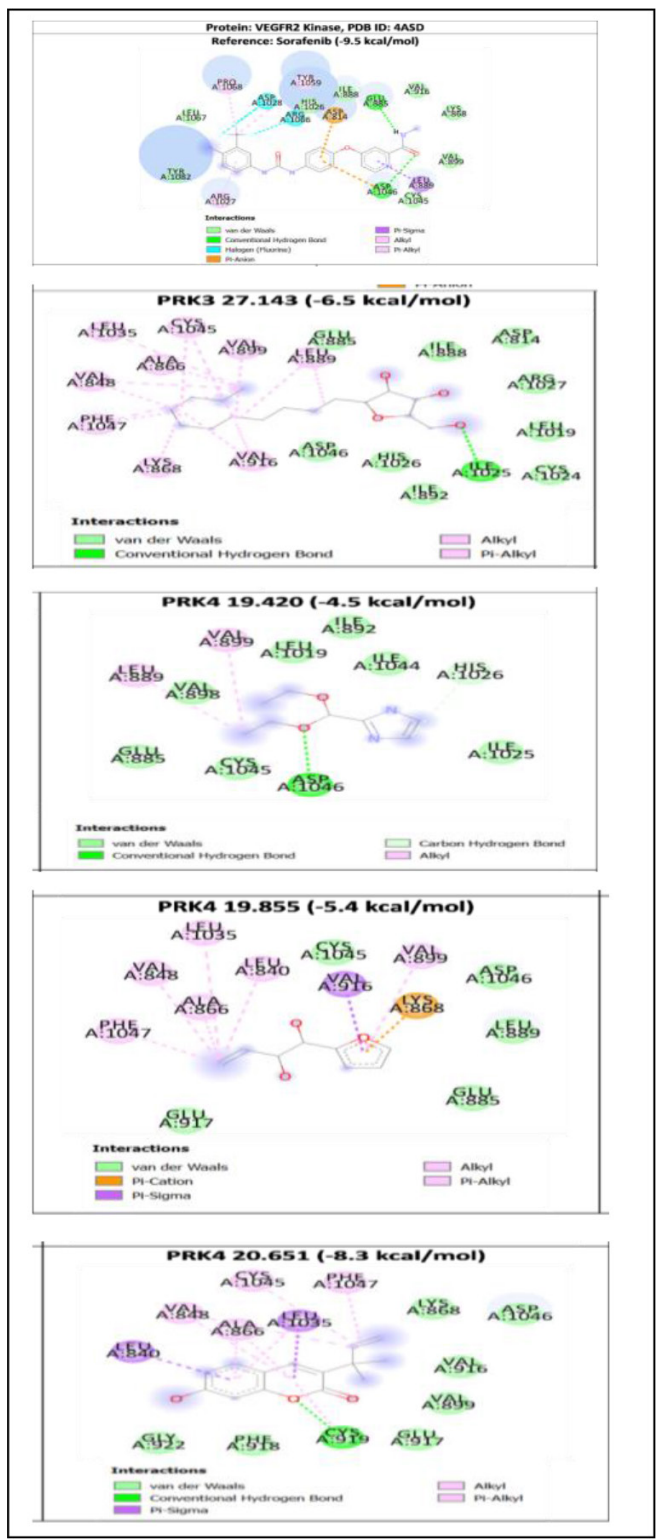

Figure 3: Docking interactions with VEGFR2 Kinase.

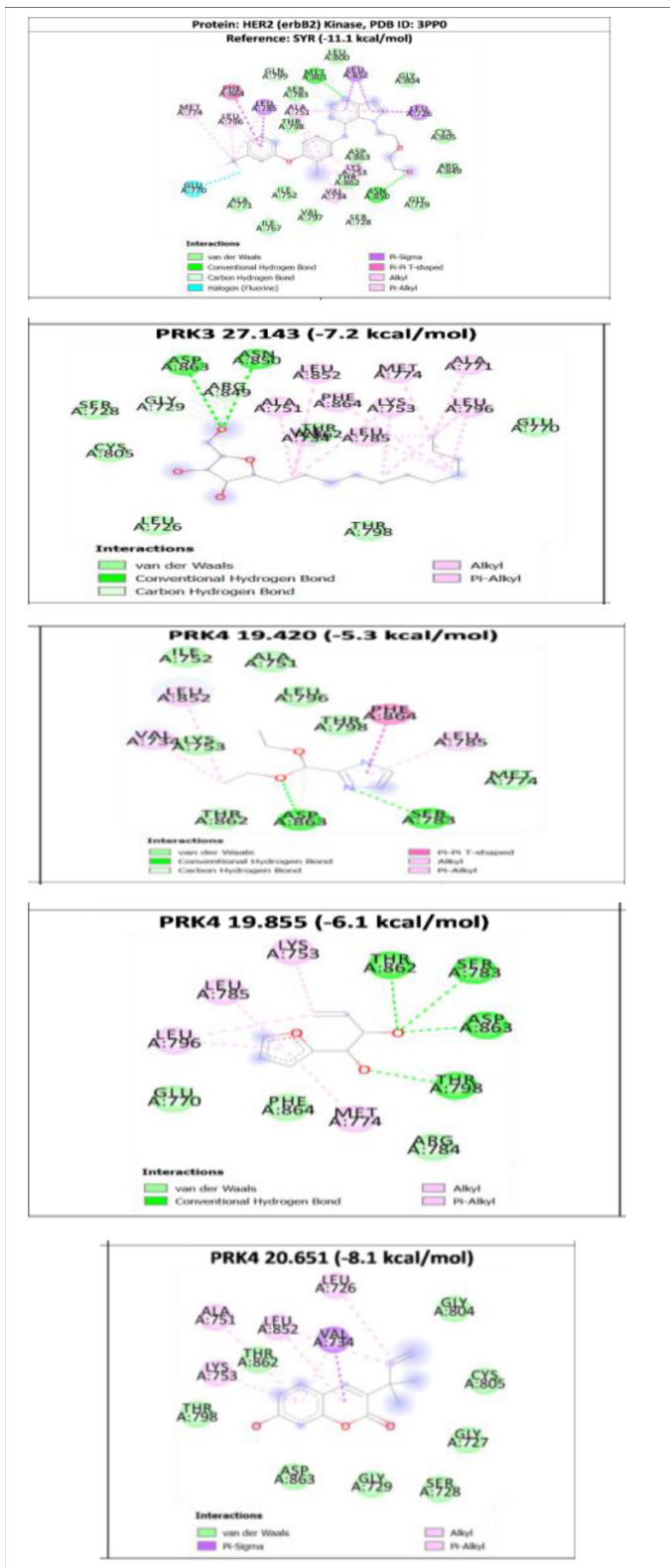

Figure 4: Docking interactions with HER2 kinase.

for TLC analysis of NCHAE was specific to determine alkaloids and phenolic compounds. Thus, the spots observed on TLC plate represent alkaloids and phenolic compounds. The literature reveals that the plants with similar phytocompounds screened for cytotoxic activity using many models and reported to possess considerable cytotoxic activity. Hence, cytotoxic potential of the extract was determined on MCF7 (breast cancer), A549 (lung cancer) and HepG2 (liver cancer) cell lines. These cell lines represent few of the major cancers spreading across the world and leading to death of the patients. The $\mathrm{IC}_{50}$ values of the extract indicates its excellent cytotoxic potential against the respective cell lines. Hence, to isolate the major compounds responsible for the activity, the extract subjected to column chromatography on silica gel stationary phase. Different fractions were collected and based on TLC analysis the fractions were combined. The GC-MS study of the selected fractions has shown compounds with furan, imidazole, furanyl, coumarin etc rings with substitution at different positions. Some steroidal derivatives also reported in GC-MS data. The literature reveals that the compounds of 


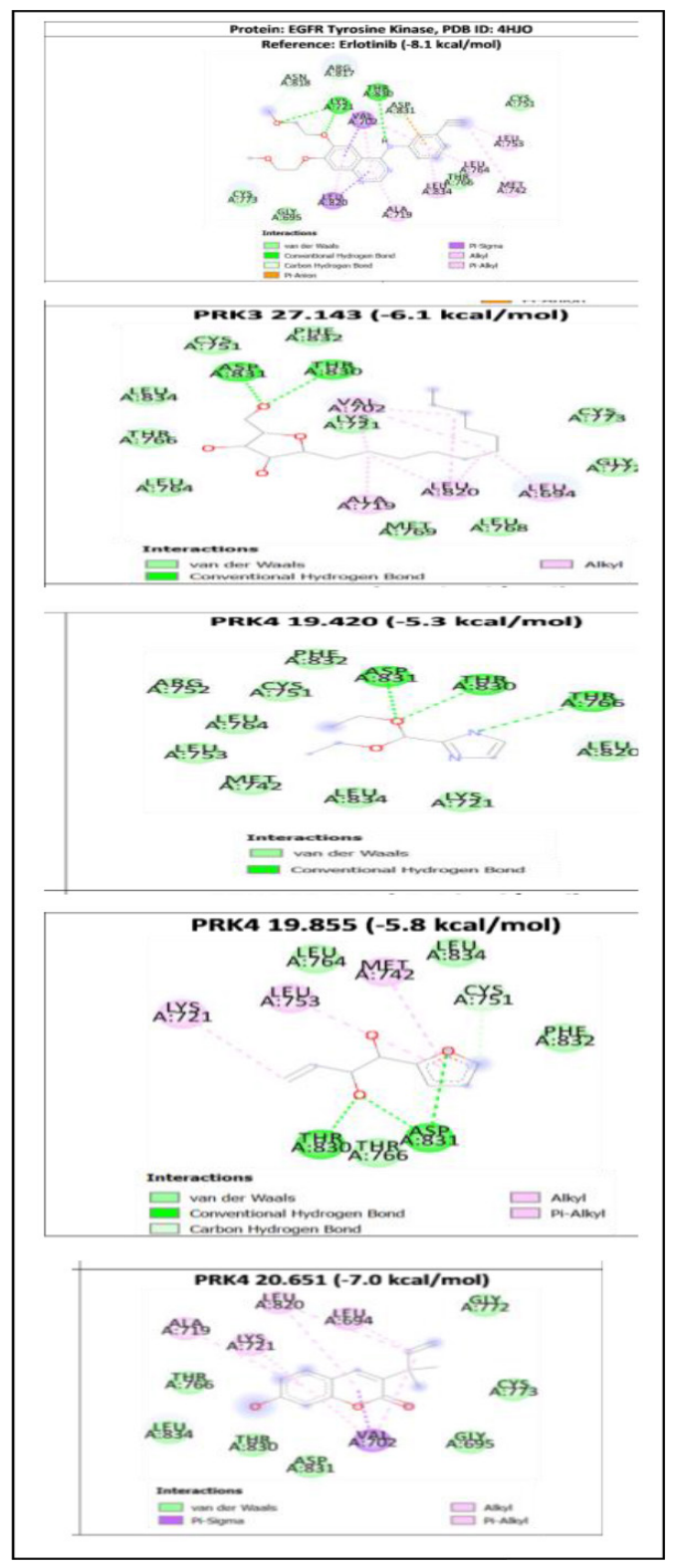

Figure 5: Docking interactions with EGFR Kinase.

similar chemistry had shown considerable anticancer potential in in-vitro studies and in docking studies also. ${ }^{6-8}$ Hence, from the reported list compounds, such compounds were chosen to carryout docking on respective anticancer target proteins. The output files generated in the molecular docking calculations were analysed using the discovery studio visualizer. Sorafenib, standard drug for liver cancer (protein kinase inhibitor) was taken as the reference for docking with VEGFR2 Kinase protein. ${ }^{14}$ The docking score of Sorafenib was found to be -9.5Kcal/mol. The four compounds PRK3 27.143, PRK4 19.420, PRK4 19.855 and PRK4 20.651 showed comparable docking scores of -6.5, -4.5, -5.4 and $-8.3 \mathrm{Kcal} / \mathrm{mole}$ respectively. The $2 \mathrm{D}$ protein ligand interactions diagrams of all the compounds represented in Figure 3. It was found that PRK4 20.651 exhibited better docking score among the four compounds. It showed alkyl interactions with CYS1045 and vanderwaals interactions with LYS868, VAL899, VAL916 and ASP1046 which were similar to the reference compound. SYR, a selective HER2 inhibitor was taken as the reference for docking with HER2 (ErbB2) Kinase protein. The docking score of it was found to be $-11.1 \mathrm{Kcal} / \mathrm{mole}$ while the docking scores of the four ligands under study were found as-7.2, -5.3, -6.1 and- $8.1 \mathrm{Kcal} / \mathrm{mole}$ respectively. The $2 \mathrm{D}$ protein ligand interaction diagrams are represented in Figure 4. It was found that PRK4 20.651 exhibited good docking score among the four ligands. PRK4 20.651 showed Vander Waal interactions with SER728, GLY729, THR798, GLY804, CYS805, THR862 and ASP863; pi-alkyl interactions with ALA751, LYS753 and LEU852; alkyl interactions with LEU726; pi-sigma interactions with VAL734. These interactions are similar to those of reference compound..$^{15,16}$

Erlotinib (tyrosine kinase inhibitor, anti-neoplastic agent for non-small cell lung cancer) was taken as the reference for docking with EGFR Tyrosine Kinase and the docking score of it was found to be $-8.1 \mathrm{kcal} / \mathrm{mol}$. The docking scores of the four ligands under study were found as -6.1 , $-5.3,-5.8$ and $-7.0 \mathrm{kcal} / \mathrm{mol}$ respectively. The $2 \mathrm{D}$ protein ligand interaction diagrams of all the compounds are represented in Figure 5. It was found that PRK4 20.651 exhibited better docking score among the four compounds. It exhibited vanderwaals interactions with GLY695, THR766, CYS773, THR830, ASP831 and LEU834; pi-alkyl interactions with ALA719, LYS721 and LEU820; pi-sigma interactions with VAL702. These interactions are comparable to those of reference compound Erlotinib. ${ }^{17}$

\section{ACKNOWLEDGEMENT}

The authors are thankful to management of G. Pulla Reddy College of Pharmacy for providing facilities to carry out this research work. Mr. P Ravi Kumar is expressing heartfelt gratitude to Prof. Arvind Kumar Rengan, Mr. Basheeruddin Alvi, IIT Hyderabad; Dr. Ravi Kiran Alvala, Associate Professor, Dr. Sama Venkatesh, Professor Department of Pharmacognosy, GPRCP, Hyderabad.

\section{CONFLICT OF INTEREST}

The authors declare no conflicts of interest.

\section{ABBREVIATIONS}

GC-MS: Gas Chromatography coupled with Mass Spectroscopy; TLC: Thin Layer Chromatography; MTT: 3-(4, 5-dimethythiazol- 2-yl)-2; 5-diphenyl tetrazolium bromide; DMEM: Dulbecco's Modified Eagles Medium; EDTA: Ehylene Diamine Tetra Acetic acid; PBS: Phosphate Buffer Saline; FBS: Foetal Bovine Serum; DMSO: Dimethyl Sulfoxide; NCHAE: Neolamarckia cadamba Hydro Alcoholic Extract; MCF7: Human breast cancer; A549: Human Lung Carcinoma; HepG2: Human Liver Cancer; PDB: Protein Data Bank; VEGFR2: Vascular Endothelial Growth Factor Receptor 2; HER2: Human Epidermal Growth Factor Receptor2; EGFR: Recombinant Epidermal Growth Factor Receptor produced in E.Coli; SDF: Structure Data File.

\section{REFERENCES}

1. Kaur V, Kumar M, Kumar A, Kaur K, Dhillon VS, Kaur S. Pharmacotherapeutic potential of phytochemicals: implications in cancer chemoprevention and future perspectives. Biomed Pharmacother. 2018;97:564-86. doi: 10.1016/j.biopha.2017.10.124, PMID 29101800.

2. Pinzi L, Rastelli G. Molecular docking: shifting paradigms in drug discovery. Int J Mol Sci. 2019;20(8): 4331:1-23. doi: 10.3390/ijms20184331, PMID 31487867.

3. Iqbal J, Abbasi BA, MahmoodT, Kanwal S, Ali B, Shah SA, Khalil AT. Plant-derived anticancer agents: A green anticancer approach. Asian Pac J Trop Biomed. 2017;7(12):1129-50. doi: 10.1016/j.apjtb.2017.10.016.

4. Siegel RL, Miller KD, Fuchs HE, Jemal A. Cancer Statistics, 2021. CA Cancer J Clin. 2021;71(1):7-33. doi: 10.3322/caac.21654, PMID 33433946.

5. Dwevedi A, Sharma K, Sharma YK. Cadamba: A miraculous tree having enormous pharmacological implications. Pharmacogn Rev. 2015;9(18):107-13. doi: 10.4103/0973-7847.162110, PMID 26392707.

6. Rodrigues J, Hullatti K, Jalalpure SS, Khanal P. In-vitro cytotoxicity and in silico molecular docking of alkaloids from Tiliacora acuminata. Ind J Pharm Educ Res. 2020;54(2s):s295-300. doi: 10.5530/ijper.54.2s.86. 
7. Ramdurga B, Kumar Jat RK, Badami S. In vitro Cytotoxic and Antioxidant Activities of Careya arborea Root Extracts. Int J Pharm Investig. 2021;11(1):127-30. doi: 10.5530/ijpi.2021.1.24

8. Hemamalini G, Jithesh P, Nirmala P. In silico screening of phytochemicals identified from Acacia nilotica by GC-MS method for its anticancer activity. Int J Pharm Sci Res. 2014;5(6):2374-81.

9. Trott O, Olson AJ. Auto Dock Vina: improving the speed and accuracy of docking with a new scoring function, efficient optimization and multi threading. J Comput Chem. 2010;31(2):455-61. doi: 10.1002/jcc.21334, PMID 19499576.

10. RCSB PDB, 4ASD, crystal structure of VEGFR2 (Juxta membrane and kinase domains) in complex with sorafenib (BAY43-9006); updated 2012 April 30; [cited Sep 26 2012]]. Available from: https://www.rcsb.org/structure/4ASD.

11. RCSB PDB, 3PP0, crystal structure of the kinase domain of Human HER2 (erbB2); updated 2010 November 23; [cited Mar 30 2012]]. Available from: https://www.rcsb.org/structure/3PP0.

12. RCSB PDB, 4HJO, crystal structure of the inactive EGFR tyrosine kinase domain with erlotinib; updated 2012 October 13; [cited Nov 14 2012]]. Available from: https://www.rcsb.org/structure/4HJO.
13. Yasar Q, Zaheer Z. 4-aminoantipyrine analogs as anti-inflammatory and antioxidant agents: synthesis, biological evaluation and molecular docking studies. J Young Pharm. 2021;11(1):14-22.

14. Wilhelm S, Carter C, Lynch M, Lowinger T, Dumas J, Smith RA, Schwartz B, Simantov R, Kelley S. Discovery and development of sorafenib: a multikinase inhibitor for treating cancer. Nat Rev Drug Discov. 2006;5(10):835-44. doi: 10.1038/nrd2130, PMID 17016424.

15. Praveena A, Arthi S, Sudarmathi B. In vitro and in silico analysis to identify novel lead compound from Morinda tinctoria fruit against breast cancer. Indian J Pharm Sci. 2019;81(5):970-5. doi: 10.36468/pharmaceutical-sciences.593.

16. Aertgeerts K, Skene R, Yano J, Sang BC, Zou H, Snell G, Jennings A, Iwamoto K, Habuka N, Hirokawa A, Ishikawa T, Tanaka T, Miki H, Ohta Y, Sogabe S. Structural analysis of the mechanism of inhibition and allosteric activation of the kinase domain of HER2 protein. J Biol Chem. 2011;286(21):18756-65. doi: 10.1074/jbc.M110.206193, PMID 21454582.

17. Bareschino MA, Schettino C, Troiani T, Martinelli E, Morgillo F, Ciardiello F. Erlotinib in cancer treatment. Ann Oncol. 2007;18(6); Suppl 6:vi35-41. doi: 10.1093/annonc/mdm222, PMID 17591829

Article History: Submission Date : 27-05-2021; Revised Date : 26-06-2021; Acceptance Date : 06-08-2021.

Cite this article: Kumar RP, Naik SS and Reddy MB. In silico Evaluation of Phytocompounds of Neolamarckia cadamba (Roxb.) Stem Bark for Anticancer Activity. Int. J. Pharm. Investigation. 2021;11(3):300-5. 